NASA/CR-2001-210889

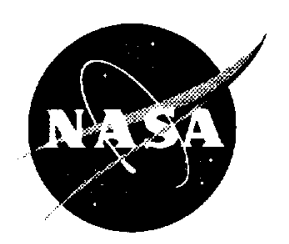

\title{
Reconfigurable Array Antenna Using Microelectromechanical Systems (MEMS) Actuators
}

Rainee N. Simons

Dynacs Engineering Company, Inc., Brook Park, Ohio

Donghoon Chun and Linda P.B. Katehi

University of Michigan, Ann Arbor, Michigan

Prepared for the

2001 AP-S International Symposium and USNC/URSI National Radio Science Meeting sponsored by the Institute of Electrical and Electronics Engineers

Boston, Massachusetts, July 8-13, 2001

Prepared under Contract NAS3-98008

National Aeronautics and

Space Administration

Glenn Research Center 
This report contains preliminary

findings, subject to revision as analysis proceeds.

Available from

NASA Center for Aerospace Information 7121 Standard Drive

Hanover, MD 21076

Price Code: A02
National Technical Information Service 5285 Port Royal Road Springfield, VA 22100

Price Code: A02

Available electronically at http://gltrs.grc.nasa.gov/GLTRS 


\title{
RECONFIGURABLE ARRAY ANTENNA USING MICROELECTROMECHANICAL SYSTEMS (MEMS) ACTUATORS
}

\author{
Rainee N. Simons \\ Dynacs Engineering Company, Inc. \\ NASA Glenn Research Center \\ 21000 Brookpark Road, Mail Stop 54-8 \\ Cleveland, Ohio 44135 \\ Donghoon Chun and Linda P.B. Katehi \\ University of Michigan \\ Radiation Laboratory, EECS Department \\ Ann Arbor, Michigan 48109-2122
}

\begin{abstract}
The paper demonstrates a patch antenna integrated with a novel microelectromechanical systems (MEMS) actuator for reconfiguring the operating frequency. Experimental results demonstrate that the center frequency can be reconfigured by as much as 1.6 percent of the nominal operating frequency at K-Band. In addition, a novel on-wafer antenna pattern measurement technique is demonstrated.
\end{abstract}

\section{INTRODUCTION}

Recently there has been tremendous interest in planar antennas capable of dynamically reconfiguring the radiation pattern to provide horizon-to-horizon scan coverage over a wide frequency range, through geometric reconfiguration [1]. These capabilities are possible through the use of microelectromechanical systems (MEMS) based switching and actuating devices or circuits. The MEMS devices offer the following advantages over semiconductor devices first, significant reduction in insertion loss. Second, they consume insignificant amount of power during operation. Third, higher linearity hence lower signal distortion. Typical examples of MEMS based antennas are reported in [2], [3], and [4].

In this paper, we present a new frequency reconfigurable patch antenna via use of integrated microelectromechanical systems (MEMS) actuators. The key features of this approach is, that it does not increase the antenna element dimensions, thus allowing for use in planar phased arrays. Second, each actuator requires only a single bias line for control, which implies greatly simplified construction and operation. In addition, the paper also demonstrates a novel on-wafer pattern measurement technique. The advantage of this technique is that there is no need to dice and separate the individual antennas on the wafer, thus resulting in tremendous savings in cost and time.

\section{MEMS ACTUATOR DESIGN AND FABRICATION}

A Patch antenna with two independent MEMS actuators is illustrated in Fig. 1. The antenna is fabricated on high resistivity silicon wafer $\left(\epsilon_{\mathrm{r}}=11.7, \mathrm{~h}=400 \mu \mathrm{m}\right)$ with spin-on-glass $(\mathrm{SOG})\left(\epsilon_{\mathrm{r}}=3.1, \mathrm{~h}_{1} \approx 1.5 \mu \mathrm{m}\right)$ as the dielectric support layer. Each actuator consists of a moveable metal overpass suspended over a metal stub and supported at either ends by metalized vias which are electrically connected to the patch antenna. The metal strip of length $\mathrm{L}$ and width $\mathrm{W}$ attached to the metal stub behaves as a parallel plate capacitor. The patch antenna operates at its nominal frequency as determined by the dimension $b$ when the actuator is in the OFF state. The actuator is in the ON state when the overpass is pulled down by the electrostatic force due to the bias, and the capacitance of the metal strip appears in shunt with the input impedance of the patch antenna. This capacitance tunes the patch to a lower operating frequency. 


\section{EXPERIMENTAL RESULTS AND DISCUSSIONS}

The measured return loss for the two states of the actuators are shown in Fig. 2. When both the actuators are in the OFF state, the patch resonates at its nominal operating frequency $\left(\mathrm{f}_{0}\right)$ of about $25.0 \mathrm{GHz}$. When both actuators are in the $\mathrm{ON}$ state, the $\mathrm{f}_{\mathrm{ON}}$ is $24.6 \mathrm{GHz}$. The $400 \mathrm{MHz}$ shift is about 1.6 percent of $\mathrm{f}_{0}$. To measure the E- and H-plane radiation patterns of the patch antenna, the RF probe station is modified to accommodate a small horn antenna. The horn antenna is attached to a Plexiglas ${ }^{\mathrm{TM}}$ fixture and is driven along an arc by a stepper motor. Thus the horn can measure the relative field intensity of the patch as a function of the angle from boresight. The experimental setup is shown in Fig. 3. The measured E- and $\mathrm{H}$-plane radiation patterns are shown in Fig. 4. At the present time, these actuators are being integrated into a $2 \times 2$ patch antenna array shown in Fig. 5 . The array characteristics will be presented at the symposium.

\section{CONCLUSIONS}

A novel frequency reconfigurable patch antenna with integrated MEMS actuators is presented for the first time. This patch can be dynamically reconfigured to operate at frequencies separated by about 1.6 percent of the nominal operating frequency. In addition, a novel on-wafer antenna pattern measurement technique is demonstrated.

\section{REFERENCES}

[1] J.K. Smith, "Reconfigurable Aperture Program (RECAP) - MEMS Revolutionary Impact on RF Systems," Workshop Notes: RF MEMS for Antenna Applications, 2000 IEEE Ant. and Prop. Inter. Symp., Salt Lake City, UT, July 16, 2000.

[2] D. Chauvel, et al., "A Micro-Machined Microwave Antenna Integrated with its Electrostatic Spatial Scanning," Proc. IEEE Tenth Annual Inter. Workshop on Micro Electro Mechanical Systems (MEMS 97), pp. 84-89, Nagoya, Japan, Jan. 26-30, 1997.

[3] J.-C. Chiao, et al., "MEMS Reconfigurable Vee Antenna," 1999 IEEE MTT-S Inter. Microwave Symp. Dig., vol. 4, pp.1515-1518, Anaheim, CA, June 13-19, 1999.

[4] C. Bozler, et al., "MEMS Microswitch Arrays for Reconfigurable Distributed Microwave Components," 2000 IEEE Ant. and Prop. Inter. Symp., Dig., Vol. 2, pp. 587-591, Salt Lake City, UT, July 16-21, 2000.

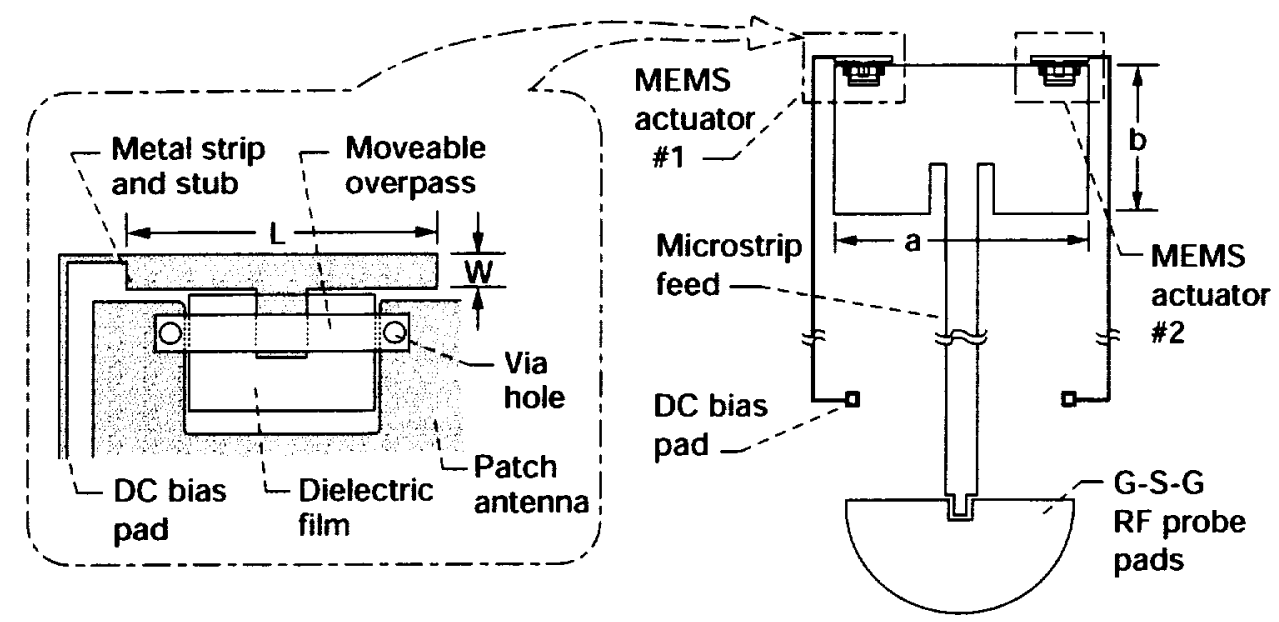

Figure 1.-Frequency reconfigurable patch antenna element with two independent MEMS actuators, $\mathrm{L}=580 \mu \mathrm{m}, \mathrm{W}=50 \mu \mathrm{m}, \mathrm{a}=2600 \mu \mathrm{m}, \mathrm{b}=1500 \mu \mathrm{m}$. 


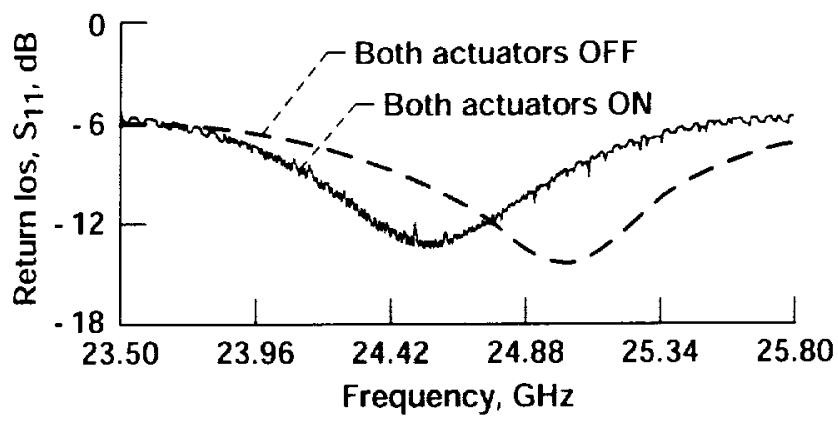

Figure 2.- Measured return loss demonstrating frequency reconfigurability with integrated MEMS actuators while maintaining good impedance match.

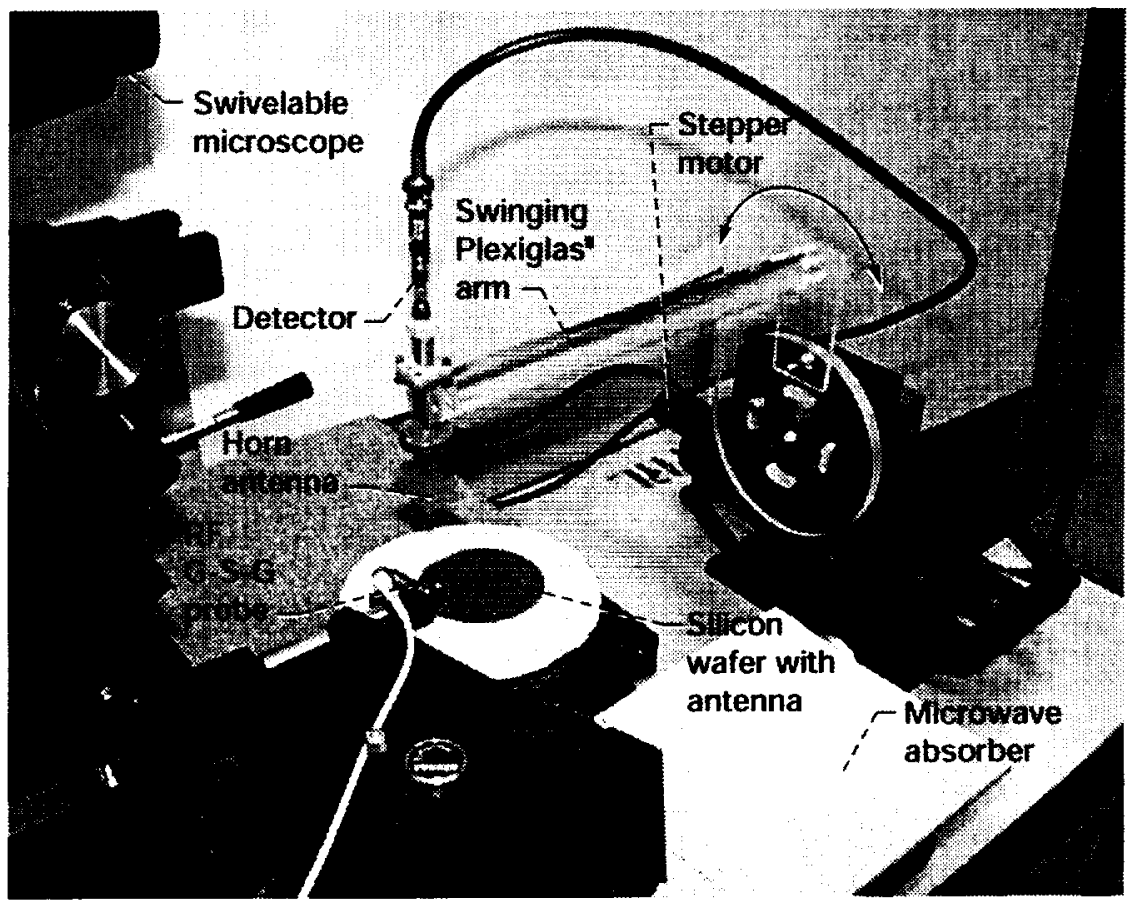

Figure 3.- Computer controlled on-wafer radiation pattern measurement set-up for MEMS actuator based patch antennas (surrounding microwave absorber panels have been removed). 


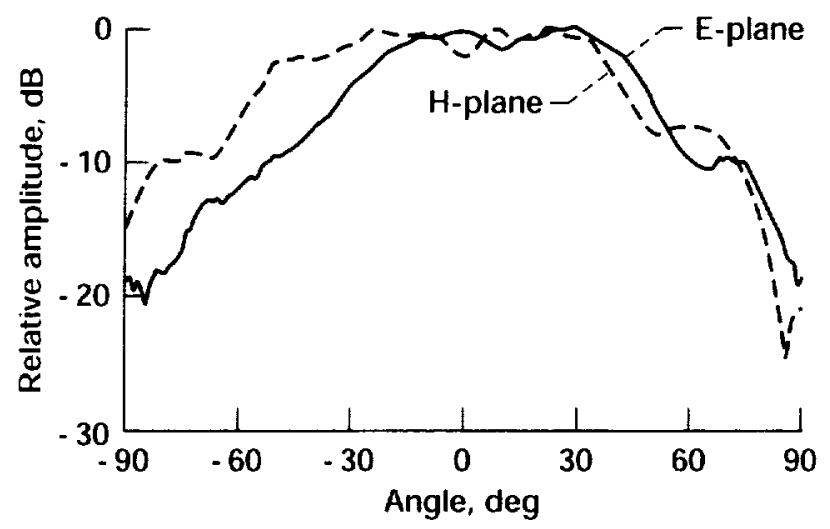

Figure 4.- Measured $\mathrm{E}$ and $\mathrm{H}$-plane radiation patterns of the patch antenna.

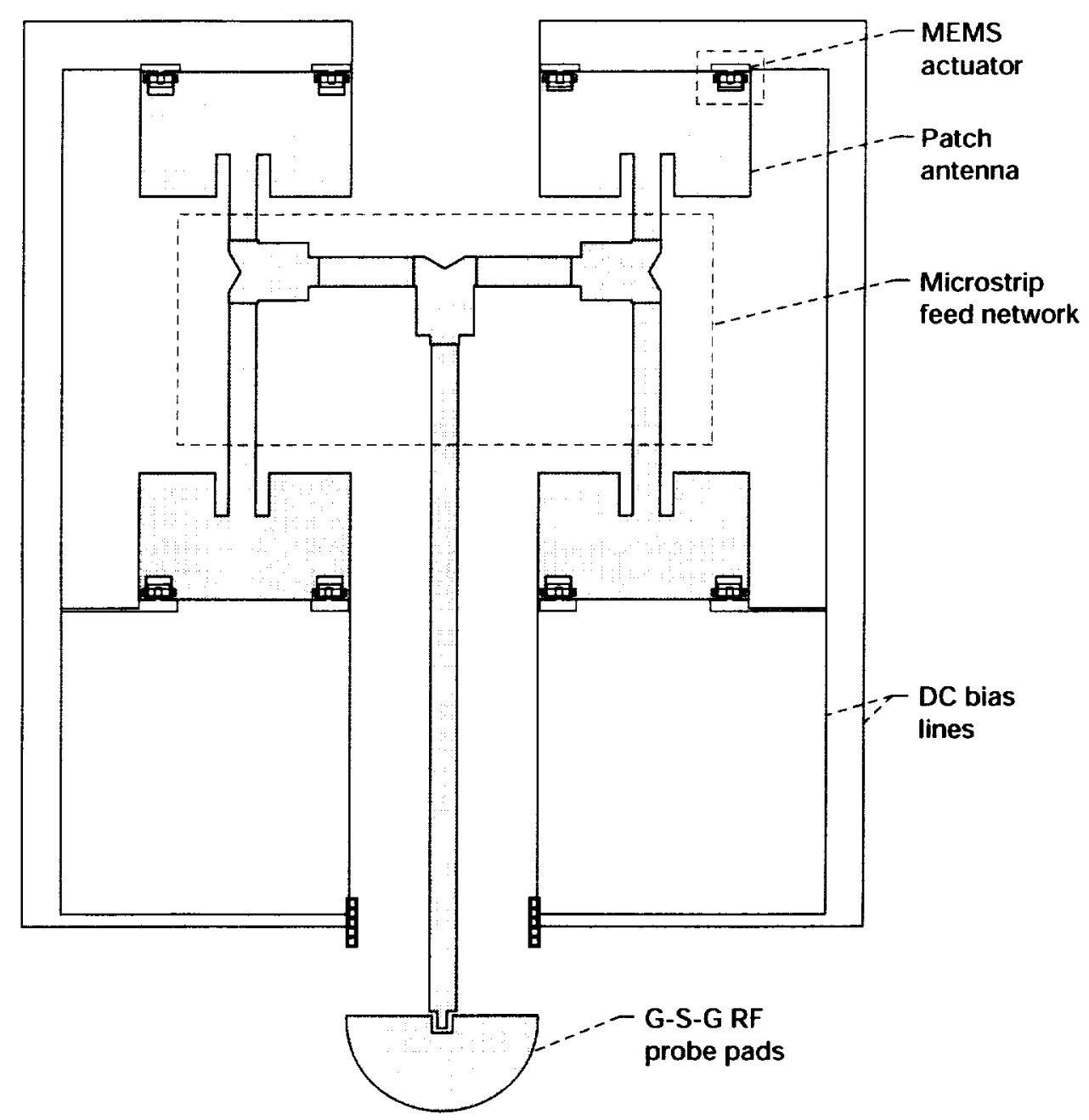

Figure 5.- Schematic showing a $2 \times 2$ patch antenna array with MEMS actuators and DC bias line for control. 

Public reporting burden for this collection of information is estimated to average 1 hour per fesponse, including the time for reviewing instructions, searching existing data sources, gathering and maintaining the data needed, and completing and reviewing the collection of information. Send comments regarding this burden estimate or any other aspect of this collection of information, including suggestions for reducing this burden. to Washington Headquarters Services, Directorate for Information Operations and Reports, 1215 Jefferson Davis Highway, Suite 1204, Artington, VA 22202-4302, and to the OHlice of Management and Budget, Paperwork Peduction Project (0704-0188). Washington, DC 20503.

\begin{tabular}{|l|l|l} 
1. AGENCY USE ONLY (Leave blank) & 2. REPORT DATE & 3. REPORT TYPE AND DATES COVERED
\end{tabular}

\section{TITLE AND SUBTITLE}

April 2001

Final Contractor Report

Reconfigurable Array Antenna Using Microelectromechanical Systems (MEMS) Actuators

6. AUTHOR(S)

Rainee N. Simons, Donghoon Chun, and Linda P.B. Katehi

7. PERFORMING ORGANIZATION NAME(S) AND ADDRESS(ES) REPORT NUMBER

Dynacs Engineering Company, Inc.

2001 Aerospace Parkway

$E-12645$

Brook Park, Ohio 44142

WU $-755-08-0 \mathrm{~B}-00$

NAS3-98008

9. SPONSORINGMONITORING AGENCY NAME(S) AND ADDRESS(ES)

10. SPONSORINGMONITORING

National Aeronautics and Space Administration

Washington, DC 20546-0001 AGENCY REPORT NUMBER

NASA CR-2001-210889

\section{SUPPLEMENTARY NOTES}

Prepared for the 2001 AP-S International Symposium and USNC/URSI National Radio Science Meeting sponsored by the Institute of Electrical and Electronics Engineers, Boston, Massachusetts, July 8-13, 2001. Rainee N. Simons, Dynacs Engineering Company, Inc., 2001 Aerospace Parkway, Brook Park, Ohio 44142; Donghoon Chun and Linda P.B. Katehi, University of Michigan, Radiation Laboratory, EECS Department, Ann Arbor, Michigan 48109-2122. Project Manager, Erick N. Lupson, Office of Acquisition, NASA Glenn Research Center, organization code 0616, 216-433-6538.

12a. DISTRIBUTIONAVAILABILITY STATEMENT

12b. DISTRIBUTION CODE

Unclassified - Unlimited

Subject Category: 33

Distribution: Nonstandard

Available electronically at http://gltrs.grc.nasa.gov/GLTRS

This publication is available from the NASA Center for AeroSpace Information, 301-621-0390.

\section{ABSTRACT (Maximum 200 words)}

The paper demonstrates a patch antenna integrated with a novel microelectromechanical systems (MEMS) actuator for reconfiguring the operating frequency. Experimental results demonstrate that the center frequency can be reconfigured by as much as 1.6 percent of the nominal operating frequency at $\mathrm{K}$-Band. In addition, a novel on-wafer antenna pattern measurement technique is demonstrated.

\begin{tabular}{|l|l|l|}
\hline 14. SUBJECT TERMS \\
Microelectromechanical systems; MEMS; Antenna; Patch; Array \\
\hline \begin{tabular}{c|c|c|} 
17. SECURITY CLASSIFICATION \\
OF REPORT \\
Unclassified
\end{tabular} & $\begin{array}{c}\text { 18. SECURITY CLASSIFICATION } \\
\text { OF THIS PAGE } \\
\text { Unclassified }\end{array}$ & $\begin{array}{c}\text { 19. SECURITY CLASSIFICATION } \\
\text { OF ABSTRACT } \\
\text { Unclassified }\end{array}$
\end{tabular}

15. NUMBER OF PAGES

10

16. PRICE CODE

$\mathrm{AO2}$

20. LIMITATION OF ABSTRACT 